\title{
Inflammatory Liposarcoma
}

National Cancer Institute

\section{Source}

National Cancer Institute. Inflammatory Liposarcoma. NCI Thesaurus. Code C6508.

A rare morphologic variant of well differentiated liposarcoma occurring most often in the retroperitoneum. It is characterized by the presence of a predominant inflammatory infiltrate composed of lymphoplasmacytic aggregates. 